\title{
Optimal quality reporting in markets for health plans
}

\author{
Jacob Glazer ${ }^{\mathrm{a}, \mathrm{b}}$, Thomas G. McGuire ${ }^{\mathrm{c}, *}$ \\ ${ }^{a}$ Boston University, Boston, USA \\ ${ }^{\mathrm{b}}$ Tel Aviv University, Tel Aviv, Israel \\ ${ }^{\mathrm{c}}$ Harvard Medical School, Department of Health care Policy, Boston, MA, USA
}

Received 1 November 2004; received in revised form 26 September 2005; accepted 14 October 2005

Available online 13 December 2005

\begin{abstract}
Quality reports about health plans and providers are becoming more prevalent in health care markets. This paper casts the decision about what information to report to consumers about health plans as a policy decision. In a market with adverse selection, complete information about quality leads to inefficient outcomes. In a Rothschild-Stiglitz model, we show that averaging quality information into a summary report can enforce pooling in health insurance, and by choice of the right weights in the averaged report, a payer or regulator can induce first-best quality choices. The optimal quality report is as powerful as optimal risk adjustment in correcting adverse selection inefficiencies.
\end{abstract}

(C) 2005 Elsevier B.V. All rights reserved.

JEL classification: III; D82

Keywords: Quality reports; Health care; Adverse selection

There is a general consensus that consumers know too little about the quality of health care services they buy, and improving what consumers know would make markets function better. Better-informed consumers may choose providers more appropriately. Furthermore, consumers and patients choosing on the basis of quality conveys incentives to providers to improve quality in the first place. These arguments motivate public regulators and business coalitions to discover and reveal characteristics of providers' quality of care. ${ }^{1}$ There is, however, a glitch in the argument:

\footnotetext{
* Corresponding author.

E-mail address: muse@ @cp.med.harvard.edu (T.G. McGuire).

1 Public payers, like Medicare (Clancy and Scully, 2003), and private coalitions, like the Leapfrog Group (Berkmeyer et al., 2000), are constructing quality reports intended to reward providers for improving quality. Medicare and the Federal Employees Health Benefit Plan (FEHBP), have made quality reports about plans or providers available to beneficiaries for some time, either as experiments or on a regular basis (Wedig and Tai-Seale, 2002).
} 
markets in health care are subject to adverse selection-related inefficiencies even in the presence of complete information (Cutler and Zeckhauser, 2000; Van de Ven and Ellis, 2000). For example, consumers' knowledge about the quality of services they anticipate receiving at a health plan drives the plan to set quality suboptimally for services that will be used by enrollees whose expected costs exceed their expected revenue (Frank et al., 2000). With consumers' information an essential element in the adverse selection causal chain, it is not self-evident that giving consumers more information will improve health care markets. ${ }^{2}$

This paper casts the decision of what information about quality to report to consumers as a policy instrument. We focus on markets for health plans, where in many cases a regulator supplies information to consumers about quality at the plans. For example, before choosing a plan, consumers in California can consult an annual report published by the state (Office of the Patient Advocate, 2003) containing plan ratings from a consumer survey and from medical record based indicators. More than 75 million people in the U.S. enroll in capitation-based health plans (Keenan et al., 2001). These health plans provide a range of health care services, including obstetric care, mental health care, oncology, vision services and so on. Potential enrollees choose a plan partly on the basis of what they anticipate will be the quality of services they receive in the plan.

Our main finding about reporting is intuitive and practical: by providing information only about the average quality of services in a health plan, rather than the quality of each of the elements of service a plan provides, a payer or regulator can give consumers helpful information but prevent a plan from setting quality of its services to try to attract a profitable mix of enrollees. The averaged report is powerful: the right weights for elements of quality in the averaged report induce a plan to produce the socially efficient quality of all services. This strong result emerges in a basic model of adverse selection where the efficient outcome is a pooling equilibrium and there are no heterogeneous tastes to be served among consumers. More complicated models of health insurance with plan heterogeneity (about which consumers would need to know) and some pricing related to risk might call for other information strategies.

Our general result, that social welfare in the case where consumers can only observe the average quality of each plan can be higher than social welfare in the case where consumers have full information about the quality of each of the services a plan offers, is somewhat surprising, especially under the assumption that consumers are rational. Consumers' rationality implies that even when they cannot observe the quality of each of the services a plan provides, and they can only observe the average quality of these services, in equilibrium, consumers do know the precise quality of each of these services. This property follows from the standard assumption that in equilibrium rational agents know the strategies of all other agents, which in our model implies that the consumers know the quality of the services each plan chooses. However, even though in both cases, the full information case and the case where consumers can only observe the average quality of each plan-individuals know the quality of each of the services each plans offers in

\footnotetext{
2 The economics literature outside of health care contains papers pointing out that in the presence of some other inefficiency, improving buyers' information need not improve the efficiency of a market equilibrium. Generally, the reason for this is that while more information may improve the quality of consumers' decisions, other parties to the exchange may behave differently when dealing with better-informed consumers, and their reactions might lead to a worse net efficiency effect of more information. For example, Schlee (1996), studies a market in which a monopolist sets price so as to equalize marginal cost and marginal revenue, but because information is imperfect, the marginal revenue reflects consumers' expectations about quality. With more information, consumers' expectations become more accurate, but may affect the shape of the marginal revenue function in ways that lead to a worse market outcome post better information (for related analyses in the general literature, see Hirshleifer, 1971; Mirman et al., 1994; Glazer and McGuire, 2003).
} 
equilibrium, the quality provided in the two cases will not be the same and the one offered in the latter case may be more efficient than the one offered in the first case. Thus, by revealing to consumers only the average quality of the different services a plan offers, a public regulator may be able to alter the quality of services offered by the plan without actually damaging what the consumers know about these qualities in equilibrium.

After a brief review of the policy context in Section 1, Section 2 modifies the model introduced by Rothschild and Stiglitz (1976), in order to demonstrate the inefficiencies due to adverse selection that may emerge in competitive insurance markets. Section 3 reviews the familiar result that if consumers can observe quality, the market equilibrium leads to inefficient quality profiles. ${ }^{3}$ Section 4 changes what consumers observe to some "average" of the quality elements in a plan. We show in this case there is a unique pooling equilibrium associated with each weighted average quality report. Section 5 establishes that a payer or regulator can achieve the first-best quality profile by choice of the weights in the average report. Our analysis implies that regulation of quality reports can be a powerful tool for improving the efficiency of health insurance markets. Section 6 considers some extensions and reconsiders some of our assumptions. Section 7 contains some brief final comments.

\section{Quality of care and adverse selection in health care}

Following a series of reports about the frequency of poor quality and the impact of poor quality on outcomes and costs, the quality of health care is attracting attention throughout the health care sector. ${ }^{4}$ Some quality problems are simple "medical errors" in which decisions made, including those about choice of techniques or technologies, would be revised if management or physicians were aware of best practices (Institute of Medicine, 1999). Other quality problems are systemic and due to "standard operating procedures" that fail to make full use of information systems or embody sufficient checks on human error (Classen and Kildgridge, 2002; Institute of Medicine, 2001). The quality problems that could be addressed with reporting to consumers are different: plans do not always have the incentives to provide the socially efficient level of care (Galvin and Milstein, 2002), and altering incentives can, therefore, be part of the solution (Sage et al., 2003). The most pervasive incentive problem in health care markets is the problem of adverse selection (Van de Ven and Ellis, 2000).

The fundamental problem of adverse selection is that risk bearing plans have incentives to discourage enrollment by potential members whose expected revenue falls short of expected costs. It has been known for some time that in a population facing choice, persons joining managed care plans are less costly than those staying in fee-for-service (Hellinger, 1995), though by itself, this is not necessarily associated with an inefficiency (Pauly, 1985). Efficiency problems stem from actions a plan takes to discourage enrollment of the likely financial losers. In public and private health insurance in the U.S., provisions requiring "open enrollment" prohibit plans from excluding eligible enrollees. Instead, plans can discourage enrollment by costly potential enrollees

\footnotetext{
${ }^{3}$ The model set up is similar to that in Glazer and McGuire (2000), with the exception of our treatment of the premium paid to plans. Glazer and McGuire applied the model introduced by Rothschild and Stiglitz (1976), to illustrate the limitations of the conventional risk adjustment mechanisms and to demonstrate how risk adjustment weights should be structured in order to optimally address the quality distortion problems due to adverse selection incentives in managed care. In this paper there is no risk adjustment and a plan is paid the same for all enrollees.

4 The March/April (2003) issue of Health Affairs contains a number of policy-related papers on health care quality. The Institute of Medicine has produced a number of important reports on quality, a recent one being IOM (2003).
} 
by providing a low quality of care of the services these enrollees are likely to use. Incentives to distort an insurance plan to discourage demand from "bad risks" were integral to one of the first models of insurance markets (Rothschild and Stiglitz, 1976), and these same ideas have been applied to health insurance (Glazer and McGuire, 2000; Newhouse, 1996) where the practice has been termed "service-level selection." It is generally recognized that the "quality problem" in managed care plans varies by service, and that plans have the means and the motive to ration care more tightly for some services and less tightly for others (Luft and Miller, 1988; Newhouse, 2002).

An emerging empirical literature confirms the presence of service-level selection activities by health plans. Frank et al. (2000) derived the characteristics of services that would be subject to under and over provision in managed care, and found that the incentives to ration various services varied considerably. One of the consistent findings in this literature so far is that the incentive to tightly ration mental health care is particularly strong. Cao (2003) finds that aged Medicare beneficiaries joining managed care plans have psychiatric Part B costs $30 \%$ lower than persons not joining managed care, whereas for physician primary care services in Part B, those joining managed care plans have $4 \%$ higher costs. Medicare beneficiaries with mental health problems appear to anticipate lower quality of care in managed care plans (in comparison with people with problems handled by general medical services), and are thereby more deterred from joining the plans relative to the average beneficiary. Cao and McGuire (2003) found evidence for servicelevel selection in Medicare by examining how greater HMO enrollment affected the distribution of patters of service use among beneficiaries remaining in regular Medicare. Mello et al. (2002) found a differential pattern of selection in Medicare for Part A and Part B costs consistent with service-level selection.

The health services literature on quality reporting in health care contains mixed findings about how reports affect consumer and plan behavior. When asked hypothetical questions, consumers say that they value reported measures of quality, and would use them in plan choice (Edgman-Levitan and Cleary, 1996; Hibbard and Jewett, 1996). Some studies of the actual effect of distribution of report card information found no discernible effect on plan choice (Chernew and Scanlon, 1998; Farley et al., 2002), but other studies have found an effect (Beaulieu, 2002; Scanlon et al., 2002). Wedig and Tai-Seale (2002) exploit a natural experiment created by the timing of report card information for federal employees and find that the reports apparently increase consumers' willingness to choose lower priced plans when they have some credible information about quality. Chernew et al. (2004) find employers' decisions about offering plans are positively related to plans' performance scores. When effects of reporting have been found, they have not always been salutary, however. Publication of physician and hospital coronary artery bypass graft $(\mathrm{CABG})$ mortality rates in New York and Pennsylvania induced providers to operate more on the less severely ill, and operate less on the more severely ill. Weighing the benefits and costs, Dranove et al. (2003) concluded the reports reduced social welfare.

\section{The model}

Suppose that there are two types of individuals, $\mathrm{L}$ and $\mathrm{H}$, who can contract two illnesses, $a$ and $c$. Illness $a$ we call an acute illness and both types of people have the same probability of contracting this illness, $p_{a}>0$. The two types are distinguished in their probability of contracting the chronic illness $c$. Let $p_{i}, i \in\{\mathrm{H}, \mathrm{L}\}$ denote the probability that a person of type $i$ contracts illness $c$. Then, $p_{\mathrm{H}}>p_{\mathrm{L}}>0$. The proportion of $\mathrm{H}$ types in the population is $\lambda, 0<\lambda<1$. Let $p_{c} \equiv \lambda p_{\mathrm{H}}+(1-\lambda) p_{\mathrm{L}}$ 
denote the (expected) probability that a randomly drawn person contracts the chronic illness. We assume that each individual knows her type. ${ }^{5}$

If a person (of either type) has illness $j, j \in\{a, c\}$, her utility from treatment will be increased by $V_{j}\left(q_{j}\right)$, where $q_{j}>0$ denotes the "quality" of the services devoted to treat illness $j$, with $V_{j}^{\prime}>0$ and $V_{j}^{\prime \prime} \leq 0{ }^{6}$ Thus, we make the simplifying assumption that the benefits from treatment are independent of one another and the same to all individuals. If a person has both illnesses, her utility, if treated, will simply be increased by $V_{a}\left(q_{a}\right)+V_{c}\left(q_{c}\right)$.

Treatment services are provided by health plans. A health plan is characterized by a quality pair $\left(q_{a}, q_{c}\right)$. Thus, if a person of type $i, i \in\{\mathrm{H}, \mathrm{L}\}$ joins a plan with a quality pair $\left(q_{a}, q_{c}\right)$, her expected utility will increase by:

$$
U_{i}\left(q_{a}, q_{c}\right)=p_{a} V_{a}\left(q_{a}\right)+p_{i} V_{c}\left(q_{c}\right)
$$

All plans have the same cost function. A plan's cost of treating a person with illness $j, j \in\{a, c\}$ at a quality level $q_{j}$ is $C_{j}\left(q_{j}\right)$, where $C_{j}^{\prime}>0, C_{j}^{\prime \prime}>0$. Thus, if a person of type $i, i \in\{\mathrm{H}, \mathrm{L}\}$ joins a plan that offers a quality pair $\left(q_{a}, q_{c}\right)$, the plan's costs are expected to increase by:

$$
C_{i}\left(q_{a}, q_{c}\right)=p_{a} C_{a}\left(q_{a}\right)+p_{i} C_{c}\left(q_{c}\right)
$$

In our model, each plan gets to choose its quality pair and the focus of our analysis is on the quality pairs that will be offered by the plans and purchased by the consumers in equilibrium. Before we study the market equilibrium, however, it is worthwhile to briefly discuss the socially efficient outcome. The socially efficient quality pair $\left(q_{a}^{*}, q_{c}^{*}\right)$ equalizes marginal benefit of treatment to marginal cost, thus solving the following pair of equations:

$$
\begin{aligned}
V_{a}^{\prime}\left(q_{a}^{*}\right) & =C_{a}^{\prime}\left(q_{a}^{*}\right) \\
V_{c}^{\prime}\left(q_{c}^{*}\right) & =C_{c}^{\prime}\left(q_{c}^{*}\right)
\end{aligned}
$$

High- and low-risk types have different probabilities of becoming ill, but once ill, receive the same utility from treatment. Thus, the efficient level of quality is independent of the probability of becoming ill and is the same for both types.

Assume that there are no copayments for use of services and that the premium paid to a plan (either by the consumers or by a payer) for each enrollee is exogenously set and is the same to all plans and for all individuals. Thus, we assume no price competition among plans and no risk adjustment. ${ }^{7}$ More specifically, throughout the paper we assume that premium is set at $r^{*}$, where

$$
r^{*}=p_{a} C_{a}\left(q_{a}^{*}\right)+p_{c} C_{c}\left(q_{c}^{*}\right)
$$

Thus, the premium is set such that the plan is expected to break even if it offers the socially efficient quality pair $\left(q_{a}^{*}, q_{c}^{*}\right)$ and attracts randomly drawn individuals from the entire population. Further assume that all individuals must choose a plan and plans must accept every applicant. Each individual can choose only one plan and each plan can offer only one quality pair $\left(q_{a}, q_{c}\right)$.

\footnotetext{
5 For more discussion of the assumptions in this section, see Glazer and McGuire (2000).

6 The economic literature models quality in two ways: as a form of quantity rationing, as here and in Pauly and Ramsey (1999), or as a shadow price as in Keeler et al. (1998), or Frank et al. (2000). When consumers are identical in their demands given they are ill, and differ only in the probability of having an illness, the two approaches are equivalent.

7 The role of risk adjustment as an alternative mechanism to address problems of adverse selection is discussed in Section 6.
} 
The order of moves in our model is as follows: first plans (simultaneously) choose their quality pair $\left(q_{a}, q_{c}\right)$, then individuals choose plans on the basis of whatever information they have about plans' quality and plans collect a revenue of $r^{*}$ per enrollee, finally each individual's health state (whether she has illness $a$ and/or $c$ ) is realized and plans pay the costs of treatment.

We will study the competitive equilibrium in two situations, one where individuals can fully observe each plan's quality pair when they choose a plan and the other where individuals can only observe a weighted average of the two dimensions of each plan's quality.

\section{Consumers can fully observe quality}

Assume that, before choosing a plan, individuals can fully observe the quality profile $\left(q_{a}, q_{c}\right)$ of each plan. Our definition of a competitive equilibrium in this case is similar to that of Rothschild and Stiglitz (1976). A competitive equilibrium in this market is a set of quality pairs such that, when individuals choose plan to maximize expected utility, (i) no quality pair in the equilibrium set makes negative expected profit and (ii) there is no quality pair outside the equilibrium set that if offered, will make a positive profit.

The following proposition builds on Rothschild and Stiglitz (1976) and Glazer and McGuire (2000).

Proposition 1. Suppose that individuals can observe the quality pair of each plan. If $\lambda$ (the proportion of the $H$ types in the population) is sufficiently large, then a competitive equilibrium exists and is characterized by two quality pairs. ${ }^{8}$ H types choose a plan that offers the quality pair:

$$
\begin{aligned}
\left(q_{a}^{\mathrm{H}}, q_{c}^{\mathrm{H}}\right)= & \underset{\mathrm{argmax}}{\operatorname{argma}} U_{\mathrm{H}}\left(q_{a}, q_{c}\right) \\
& \text { s.t. } \quad C_{\mathrm{H}}\left(q_{a}, q_{c}\right)=r^{*}
\end{aligned}
$$

and L types choose a plan that offers the quality pair:

$$
\begin{aligned}
\left(q_{a}^{\mathrm{L}}, q_{c}^{\mathrm{L}}\right)= & \operatorname{argmax} \quad U_{\mathrm{L}}\left(q_{a}, q_{c}\right) \\
& \text { s.t. } \quad C_{\mathrm{L}}\left(q_{a}, q_{c}\right)=r^{*} \\
& \text { and } U_{\mathrm{L}}\left(q_{a}, q_{c}\right)=U_{\mathrm{H}}\left(q_{a}^{\mathrm{H}}, q_{c}^{\mathrm{H}}\right)
\end{aligned}
$$

The proof of the proposition above is well established (see Glazer and McGuire, 2000). The reason that the socially efficient quality pair $\left(q_{a}^{*}, q_{c}^{*}\right)$ cannot be an equilibrium pair is that if all plans offer this quality profile, each (single) plan will have an incentive to deviate to a different pair, say $\left(q_{a}^{\prime}, q_{c}^{\prime}\right)$ with a better acute care (i.e., $\left.\left(q_{a}^{\prime}>q_{a}^{*}\right)\right)$ and a worse chronic care (i.e., $\left.\left(q_{c}^{\prime}<q_{c}^{*}\right)\right)$, attracting only the $\mathrm{L}$ types and making a strictly positive profit. The equilibrium in the full information case is described in Fig. 1. The curves $r_{i}^{*}, i=\mathrm{H}$, L represent all plans, i.e., pairs of $\left(q_{a}, q_{c}\right)$ that break even if the plan attracts only individuals of type $i$, when the premium is $r^{*}$. The points denoted by $q_{i}, i=\mathrm{H}$ or $\mathrm{L}$, depict the plan chosen by type $i$ in equilibrium, i.e., $q_{i}=\left(q_{a}^{i}, q_{c}^{i}\right)$. Curves $u_{i}, i=\mathrm{H}, \mathrm{L}$, represent type $i$ 's indifference curves that goes through the point $q_{i}$. The curve $r^{*}$ represents all plans that break even if the plan attracts a random sample of the population, and the point $q^{*}$ depicts the socially efficient levels of quality. We can see, therefore, that in a market

\footnotetext{
${ }^{8}$ The exact condition is that $\lambda$ should be sufficiently large so that $U_{\mathrm{L}}\left(q_{a}^{\mathrm{L}}, q_{c}^{\mathrm{L}}\right) \geq U_{\mathrm{L}}\left(q_{a}, q_{c}\right)$ for every $\left(q_{a}, q_{c}\right)$ for which $p_{a} C_{a}\left(q_{a}\right)+p_{c} C_{c}\left(q_{c}\right)=r^{*}$.
} 


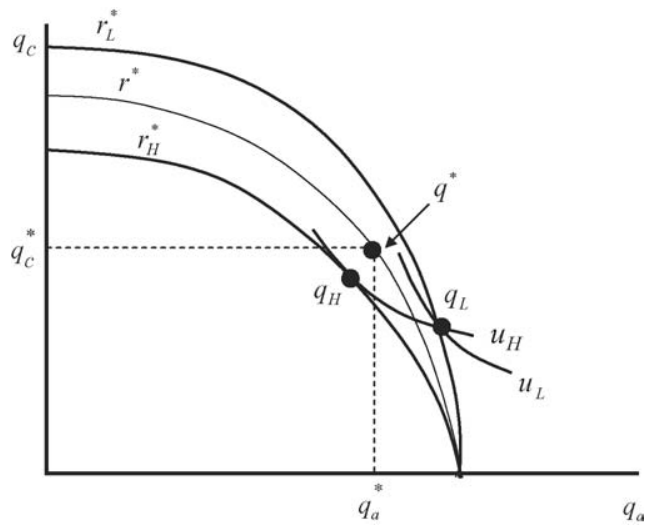

Fig. 1. Equilibrium when quality is observable.

with full information and no risk adjustment, plans will not offer the socially efficient quality profile in equilibrium. ${ }^{9}$

In what follows we study the case where consumers cannot observe any of the quality elements composing the good and the only information they can rely on is the average quality of these elements. One could, of course, allow for many other information configurations. If, for example, in our model consumers could not observe one of the two elements of the product's quality and could perfectly observe the other, each plan would set the "unobserved" element of quality at its lowest feasible level and the level of the other element at its highest level so that it breaks even given the premium and given that it attracts a random sample of the population. If both elements of quality were unobservable by consumers, all plans would have set both of them at their lowest feasible level. The case analyzed below is the one we believe is the most interesting as it demonstrates the potential "power" of quality indices as regulatory instruments.

\section{Individuals can only observe average quality}

In many markets, including in health care, individuals must chose complicated products or services on the basis of quality summaries without being able to observe all of the quality elements composing the good. For a given quality pair $\left(q_{a}, q_{c}\right)$ chosen by a plan and $0<\alpha<1$, let

$$
\bar{q}_{\alpha}=\alpha q_{a}+(1-\alpha) q_{c}
$$

be the (weighted) average quality of this plan. Assume that individuals cannot observe $\left(q_{a}, q_{c}\right)$ but they can observe $\bar{q}_{\alpha}$ of each plan. That is, individuals cannot observe the quality of each of the services a plan offers, but they can observe some summary indicator of the plan's quality profile.

The fact that individuals can only observe the "average" quality of each plan, and not the quality of each service a plan offers, will affect the market equilibrium. The profitability of any quality pair $\left(q_{a}, q_{c}\right)$ depends on individuals' beliefs about the quality of each service, given that they can

\footnotetext{
${ }^{9}$ The reason for inefficiency of equilibrium is that plans cannot change different premiums to the two types. This could be because plans cannot observe type, or, because regulation requires equal premiums.
} 
only observe the average quality of the two services. In order to analyze competitive equilibrium in the market where individuals only observe average quality of each plan, one therefore needs to generalize the earlier competitive equilibrium concept to incorporate individuals' beliefs about quality in the definition of equilibrium. We apply the following definition (which is in the spirit of Perfect Bayesian and Sequential equilibria).

A competitive equilibrium is a set of quality pairs offered by plans and a set of individuals' belief functions that specify for each individual her beliefs about the quality pair of each plan, for every possible average quality $\bar{q}_{\alpha}$ of that plan, ${ }^{10}$ such that: (i) each plan maximizes its profit given all the other pairs offered and given individuals' beliefs, (ii) each individual chooses a plan that offers her the highest expected utility given her information and given her beliefs, (iii) there is no quality pair outside the equilibrium set that if offered will make a positive profit and (iv) in equilibrium, individuals' beliefs are confirmed.

The following lemma will be important for our further analysis of this case.

Lemma 1. Assume some $\alpha, 0<\alpha<1$, and suppose that all individuals can only observe the average quality $\bar{q}_{\alpha}$ of each plan. If, in equilibrium, a plan offers the quality pair $\left(q_{a}^{\prime}, q_{c}^{\prime}\right)$ and a share $\lambda^{\prime}, 0 \leq \lambda^{\prime} \leq 1$, of the individuals that join this plan are of type $H$, then it must be that

$$
\frac{p_{a} C_{a}^{\prime}\left(q_{a}^{\prime}\right)}{\alpha}=\frac{p_{c}^{\prime} C_{c}^{\prime}\left(q_{c}^{\prime}\right)}{1-\alpha}
$$

where

$$
p_{c}^{\prime}=\lambda^{\prime} p_{\mathrm{H}}+\left(1-\lambda^{\prime}\right) p_{\mathrm{L}}
$$

Proof. Notice that Eq. (6) above is derived from the first-order conditions for the following problem:

$$
\begin{array}{ll}
\min _{\left(q_{a}, q_{c}\right)} & p_{a} C_{a}\left(q_{a}\right)+P_{c}^{\prime} C_{c}\left(q_{c}\right) \\
\text { s.t. } & \alpha q_{a}+(1-\alpha) q_{c}=\bar{q}_{\alpha}^{\prime}
\end{array}
$$

where $\bar{q}_{\alpha}^{\prime}=\alpha q_{a}^{\prime}+(1-\alpha) q_{c}^{\prime}$. Thus, if $\left(q_{a}^{\prime}, q_{c}^{\prime}\right)$ does not satisfy (6), the plan can offer another quality pair $\left(q_{a}^{\prime \prime}, q_{c}^{\prime \prime}\right)$, say, with the same average quality as $\left(q_{a}^{\prime}, q_{c}^{\prime}\right)$ but lower (expected) costs per enrollee. If the plan deviates to this (new) quality pair its profit will be higher since its revenue will not change (individuals see the same average quality, and therefore, do not change their beliefs about the plan's quality pair) but its costs will be lower.

The intuition for this result is quite simple and very general. Since individuals can only observe the average quality of all the services a plan offers, the plan has no incentive to provide a quality profile that yields the same average as another quality but costs more. Condition (6) above will be later referred to as the incentive compatible (IC) condition.

For a given $\alpha, 0<\alpha<1$, the curve $\operatorname{IC}(\alpha, \lambda)$, in Fig. 2, represents all quality profiles that satisfy the IC condition for the (pooling) case where $\lambda^{\prime}=\lambda$, i.e., the case where the plan attracts a random sample of the population. Increasing the weight that the averaging formula assigns to service $a$ by

\footnotetext{
10 Formally, the assumption is that for each consumer $k$ there is a belief function $B_{k}: R_{+} \rightarrow R_{+} \times R_{+}$, such that for every average quality $\bar{q}_{\alpha}$, the function specifies beliefs about a plan's quality profile $\left(q_{a}, q_{c}\right)$ given that average quality. In order to simplify the analysis, we assume that a consumer's beliefs depend only on the plan's average quality and not on the plan's identity or the average quality of the other plans.
} 


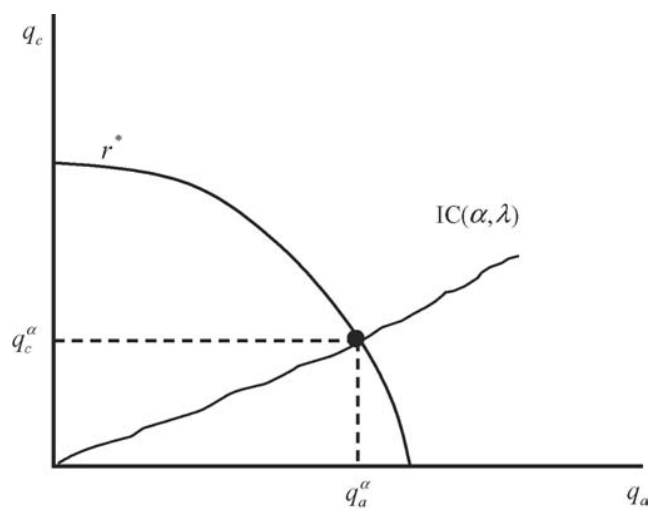

Fig. 2. The equilibrium quality profile in the averaged information case.

increasing $\alpha$ shifts to the right the set of quality pairs that the plan may offer in equilibrium. The curve $r^{*}$ in that figure depicts all quality profiles that satisfy the zero profit (pooling) condition:

$$
p_{a} C_{a}\left(q_{a}\right)+p_{c} C_{c}\left(q_{c}\right)=r^{*}
$$

As the following proposition shows, the quality pair that is located at the intersection of these two curves, denoted by $\left(q_{a}^{\alpha}, q_{c}^{\alpha}\right)$, is the unique quality pair offered by the plans in the competitive equilibrium in the case where individuals can only observe the average quality of each plan.

Proposition 2. Assume some $\alpha, 0<\alpha<1$. Suppose that all individuals can only observe the average quality $\bar{q}_{\alpha}$ of each plan. A unique competitive equilibrium exists. In equilibrium all plans offer the same quality pair $\left(q_{a}^{\alpha}, q_{c}^{\alpha}\right)$ characterized by:

$$
\frac{p_{a} C_{a}^{\prime}\left(q_{a}^{\alpha}\right)}{\alpha}=\frac{p_{c} C_{c}^{\prime}\left(q_{c}^{\alpha}\right)}{1-\alpha}
$$

and

$$
p_{a} C_{a}\left(q_{a}^{\alpha}\right)+p_{c} C_{c}\left(q_{c}^{\alpha}\right)=r^{*}
$$

Proof. Assume some $\alpha, 0<\alpha<1$ and let

$$
\bar{q}_{\alpha}^{*}=\alpha q_{a}^{\alpha}+(1-\alpha) q_{c}^{\alpha}
$$

be the average quality (that all individuals observe) of a plan that offers the quality pair $\left(q_{a}^{\alpha}, q_{c}^{\alpha}\right)$.

In order to show that $\left(q_{a}^{\alpha}, q_{c}^{\alpha}\right)$ is an equilibrium, assume that (all) individuals' beliefs are such that for every average quality $\left(\bar{q}_{\alpha}\right)$ they observe, and for every plan, individuals believe that the plan has chosen the quality profile that yields $\bar{q}_{\alpha}$ and that satisfies the IC condition, with $\lambda^{\prime}=\lambda$. Thus, individuals believe that among all quality profiles that yield a particular average quality, the plan offers the one located on the curve $\operatorname{IC}(\alpha, \lambda)$ in Fig. 2. Given these beliefs, one can see that if all plans offer the quality pair $\left(q_{a}^{\alpha}, q_{c}^{\alpha}\right)$, individuals beliefs will be confirmed.

In order to show that all plans offering $\left(q_{a}^{\alpha}, q_{c}^{\alpha}\right)$ is an equilibrium, it remains to be shown that no plan can offer another quality profile and make a strictly positive profit. Suppose that some plans (at least one) offer the quality pair $\left(q_{a}^{\alpha}, q_{c}^{\alpha}\right)$ and one plan offers a different quality pair $\left(q_{a}^{\prime}, q_{c}^{\prime}\right)$ with average quality $\bar{q}_{\alpha}^{\prime}$. If $\bar{q}_{\alpha}^{\prime}=\bar{q}_{\alpha}^{*}$ individuals will believe that the plan's quality pair is $\left(q_{a}^{\alpha}, q_{c}^{\alpha}\right)$, 
the plan will attract a random sample of the population and will lose money since its costs must be higher than the costs of producing $\left(q_{a}^{\alpha}, q_{c}^{\alpha}\right)$. If $\bar{q}_{\alpha}^{\prime}>\bar{q}_{\alpha}^{*}$ all individuals will choose this (new) plan believing that its quality pair is on the curve $\operatorname{IC}(\alpha, \lambda)$ in Fig. 2 but to the right of $\left(q_{a}^{\alpha}, q_{c}^{\alpha}\right)$. In this case the plan will lose money since any quality pair with an average quality higher than $\bar{q}_{\alpha}^{*}$, that attracts all individuals, must be above the zero profit pooling curve $r^{*}$, as it is at least as expensive as the quality pair that yield this same average quality and satisfies the IC condition. If $\bar{q}_{\alpha}^{\prime}<\bar{q}_{\alpha}^{*}$ then all individuals will believe that $q_{a}^{\prime}<q_{a}^{\alpha}$ and $q_{c}^{\prime}<q_{c}^{\alpha}$ and none of them will choose this (new) plan.

In order to show that $\left(q_{a}^{\alpha}, q_{c}^{\alpha}\right)$ is the unique equilibrium, notice first that there cannot be any other (pooling) equilibrium in which each plan attracts a random sample of the population. Suppose, therefore, that there exists an equilibrium in which one plan offers the quality pair $\left(q_{a}^{\prime}, q_{c}^{\prime}\right)$ and $\lambda^{\prime}$, of its individuals are of the type $\mathrm{H}, 0 \leq \lambda^{\prime} \leq 1$, and another plan offers the quality pair $\left(q_{a}^{\prime \prime}, q_{c}^{\prime \prime}\right)$ and $\lambda^{\prime \prime}$, of its individuals are of type $\mathrm{H}, 0 \leq \lambda^{\prime \prime} \leq 1$, with $\lambda^{\prime \prime}>\lambda^{\prime}$. Since at least some type L's choose $\left(q_{a}^{\prime}, q_{c}^{\prime}\right)$, individuals of type $\mathrm{L}$ (weakly) prefer the quality pair $\left(q_{a}^{\prime}, q_{c}^{\prime}\right)$ over the quality pair $\left(q_{a}^{\prime \prime}, q_{c}^{\prime \prime}\right)$. Since the indifference curves in our utility functions satisfy the single-crossing property, the $\mathrm{H}$ type individuals will strictly prefer the quality pair $\left(q_{a}^{\prime}, q_{c}^{\prime}\right)$ over $\left(q_{a}^{\prime \prime}, q_{c}^{\prime \prime}\right)$ which contradicts the initial assumption that $\lambda^{\prime}<\lambda^{\prime \prime}$. These same arguments can be easily applied to the case where type L strictly prefers $\left(q_{a}^{\prime}, q_{c}^{\prime}\right)$ over $\left(q_{a}^{\prime \prime}, q_{c}^{\prime \prime}\right)$.

\section{Choosing a form of report}

Although quality ratings are available to individuals in many markets, health care has the special feature that some of these ratings are done by payers, such as when the Federal Employee Health Benefit Program or the federal Medicare program rates HMOs. Private insurers also rate the medical groups and hospitals they offer as choices to their enrollees. This section addresses the question of how to choose the weights in an averaged quality report, a function that could be assumed by a public regulator, such as a state agency, or by a payer. We will refer here to a "payer" with both payers and public regulators in mind. We conduct this analysis under the strong assumption that the firm is unable to reveal information about quality to consumers and consumers cannot find out about quality on their own. The consequences of relaxing this assumption are considered in the next section.

In the full information case, if equilibrium exists it never yields the socially optimal quality profile. As the following corollary to Proposition 2 shows, an averaged quality report can move the market equilibrium to the efficient quality profile.

Corollary 1. Suppose that all individuals can only observe the average quality of each plan and $\alpha=\alpha^{*}$, where $\alpha^{*}$ is given by:

$$
\frac{p_{a} C_{a}^{\prime}\left(q_{a}^{*}\right)}{\alpha^{*}}=\frac{p_{c} C_{c}^{\prime}\left(q_{c}^{*}\right)}{1-\alpha^{*}},
$$

then all plans offer the socially efficient quality pair $\left(q_{a}^{*}, q_{c}^{*}\right)$ in the competitive equilibrium. Fig. 3 shows this equilibrium.

Corollary 1 has two significant implications. The first is that social welfare (measured by the expected utility of a randomly drawn individual) can be higher in equilibrium where individuals can only observe the average quality of each plan than in equilibrium where individuals have full information about plans' quality. 


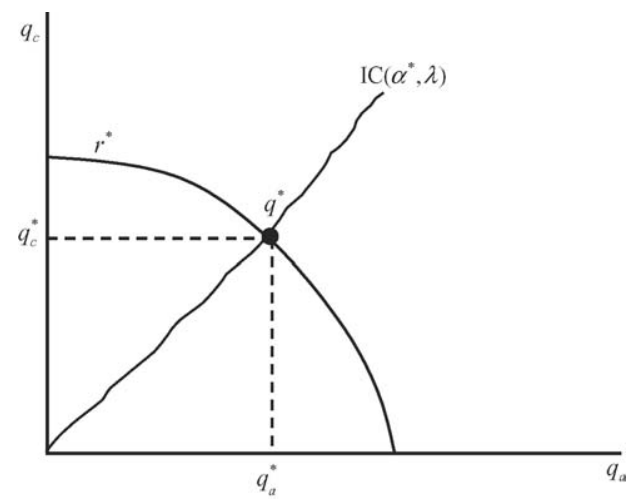

Fig. 3. Market equilibrium with optimal averaged report.

The second implication of Corollary 1 has to do with policy about information disclosure. Suppose that when choosing a health plan, individuals cannot observe the quality profile of health plans and the only information they can rely on is the information provided to them by a payer or other agency acting on their behalf. Assume that the payer can fully observe each plan's quality profile. Corollary 1 says that to maximize social surplus, the payer will not reveal all information to individuals but only the weighted average quality of each plan, where the weights come from (11).

How should weights be chosen for an averaged quality report? Eq. (11) relates the relative weights for two services, $\alpha$ and $1-\alpha$, to characteristics of two services $a$ and $c$. Eq. (11) could be rewritten as follows:

$$
\frac{\alpha^{*}}{1-\alpha^{*}}=\frac{p_{a} C_{a}^{\prime}\left(q_{a}^{*}\right)}{p_{c} C_{c}^{\prime}\left(q_{c}^{*}\right)}
$$

The relative weights on quality of services $a$ and $c$ depend on the probabilities of the two illnesses and the marginal costs of quality at the efficient quality. The quality weights are like relative prices equal to marginal cost at the efficient level of production.

Equation $\left(11^{\prime}\right)$ tells us how to use the $\alpha$ and $1-\alpha$ weights to induce a desired quality mix. Suppose it was determined with some initial setting of the weights that the quality of chronic care was too low in relation to acute care. To induce plans to put more emphasis on quality of chronic care, the payer or regulator then reduces $\alpha$ and increases $1-\alpha$, increasing the relative importance of chronic care in the averaged report. For the cost-minimizing condition $\left(11^{\prime}\right)$ to remain true, the plan must decrease $q_{a}$ and increase $q_{c}$.

\section{Extensions and reconsideration of assumptions}

\subsection{Extension: more than two services}

A natural question is whether the averaged report on quality can succeed in inducing a plan to provide efficient quality if there are more than two dimensions of quality. Although we do not provide a formal analysis, the averaged quality report mechanism generalizes readily to the case of more than two services. With only an averaged quality available to individuals, it remains 
true that the market equilibrium must be a pooling equilibrium. With many dimensions of quality, producing the reported average at the minimum cost (Lemma 1) continues to imply a unique set of quality choices that are a function of the weights on the averaged quality and the premium. Thus, in competitive (zero profit) equilibrium plans will produce the highest averaged quality given the fixed premium for a random sample of enrollees, and the quality of the various dimensions will be determined by the cost minimization decision. By choosing the weights to compose the average, a payer can direct the IC condition to intersect the pooling quality zero profit surface at the point of the desired mix of qualities.

\subsection{Extension: plans attempt to select low-risks with other mechanisms}

In our paper so far plans make decisions about the quality of services. There may be other plan design features a plan can use to attempt to attract low-risk enrollees, such as copayments, deductibles, or deciding about coverage for "optional" services, such as drugs or dental care. The first point to note about these mechanisms is that they are verifiable, and may therefore be easier to regulate directly (by mandating benefits). To the extent that they are not regulated and remain as tools for selection, the analysis we have done for service-level selection also applies to these mechanisms. In other words, if plans use insurance coverage (as was done in the original Rothschild-Stiglitz analysis) as a selection device, an averaged report of the type proposed here would address these inefficiencies as well.

We now reconsider some of our assumptions and how these might influence our conclusion about the usefulness of an averaged report. We group these into assumptions about mechanisms to achieve selection that an averaged report may not address, assumptions about strategies a regulator could use to combat selection, and assumptions about information.

\subsection{Person-specific mechanisms to select enrollees}

A health plan can take actions to target individual enrollees or potential enrollees. For example, a plan might simply deny enrollment to an applicant it anticipates would be high cost. Or, in order to discourage a current enrollee from remaining in the plan, a plan could discriminate in the quality or the accessibility of the services it offers to that enrollee. Representatives of the plan might, as an example, make it more difficult for older people to schedule appointments quickly. Open enrollment and non discriminatory provisions of contracts between payers and health plans prohibit plans from attempting to select in these ways, which does not of course mean that plans never do these things. In a conference on risk adjustment, representatives of private employers regarded open enrollment provisions as being effective in preventing plans from denying enrollment from costly employees and families (Glazer and McGuire, 2001). It should be noted, however, that the averaged quality report does not alter a plan's incentives to select in this way. This is in contrast to risk adjustment, which, by bringing revenue associated with an enrollee closer to expected cost, does mitigate these incentives.

\subsection{Other mechanisms to deal with adverse selection}

There are several mechanisms regulators can use to deal with plans' incentives to select profitable enrollees. If the quality of a service is not only observable but also verifiable a regulator or a payer can make quality part of the contract. The regulator, for example, may set up standards 
for treating chronically ill patients and reward those plans that meet these standards. The main problem with this type of mechanism, however, is that in many cases, the quality of care is not easy to verify and even if it is, putting it in the contract could make the contract very complicated. Furthermore, making quality of care part of the contract might create a whole set of new incentives not always in the direction desired by the regulator. Plans might select enrollees or perform procedures in a way that will boost their quality score.

Another mechanism to address adverses election is risk adjustment. If plans are paid more (less) for patients that are expected to cost more (less), their incentives to select enrollees are reduced. However, it is hardly ever the case that risk adjustment can completely eliminate the adverse selection problem. As long as individuals have some information about their future health care needs, that the payer cannot use as part of its risk adjusted payment scheme, incentives to select enrollees on the basis of this information will remain.

A third mechanism to lessen plans' incentives to select enrollees is cost sharing between the payer and the plan. Cost sharing can take different forms but the idea common to all of them is that the plan does not bear the full marginal health care costs of its enrollees and in particular of the most expensive ones. However, as long as the plan is held responsible for some if these costs, the incentives to select the more profitable ones still remain.

It seems, therefore, that even though there are other mechanisms to address incentives to select enrollees, none of them is powerful enough to eliminate concerns about adverse selection. Ultimately, a payer or regulator can make a choice among these approaches, and our work can be viewed as adding another tool to the set of things available to address selection.

\subsection{Consumer behavior and information}

Our analysis above calls attention to the crucial role of consumer beliefs in market equilibrium with imperfect information. We make the standard assumption that individuals can anticipate how a plan would choose qualities to produce a reported average. The literature on the effect of quality reports implies that individuals may simply be not very good at processing reports (Hibbard et al., 2000). The advantage of an averaged report from the standpoint of ease of understanding is a distinct point from the one we identify in this paper. Study of how consumers understand reports will be necessary in order to draw conclusions for the best form and information to be contained in the reports.

Another key assumption in our model is that individuals rely exclusively on information from the regulator to learn about quality. Other routes for learning may undermine a regulator's control of what individuals know: first, consumers may themselves have experience or may undertake some search for information; second, plans may have an incentive to reveal information in addition to that which is required by a regulator. Incorporating these features is likely to put restrictions on what a regulator is able to achieve.

In health insurance markets, an employer plays the role of a consumer by contracting with the plan or plans employees may choose among. An employer might want to know all elements of quality of plans, but still, in terms of what is provided to employees, would want the report that minimizes inefficiencies due to adverse selection.

This paper starts with a set of quality measures available to a regulator and asks what weights should be used. One could take another step back and ask what information should be collected on the basis of cost, accuracy, or other factors. We have sought to point out some of the benefits of use of information for purposes of addressing adverse selection that should be weighed along with these cost considerations. 


\section{Discussion}

In many sectors of the economy, quality reports integrate into market functioning in positive ways. Consumer demand for quality reports supports publication of private rating services, such as Consumer Reports, that contribute to market evaluation of quality. Quick acceptance of new ratings by consumers is not, however, to be expected. Years elapsed, for example, between the introduction of U.S. News and World Report magazine's rating of colleges and the emergence of the powerful effects (plus and minus) these ratings now have on patterns of college admissions and other practices (Avery et al., 2003). In spite of mixed results in the literature to date, quality reporting remains a plausible low-cost strategy for making improvement in the quality of health care services.

Managed care plans paid by capitation are prevalent in California for both commercial employer-based health insurance and public insurance for the elderly and poor, and reports about health plan and provider group quality are also highly developed in California. The state makes available summary ratings based on 1-3 "stars" in four categories of quality (e.g., "care for staying healthy," "care for getting better") that are based on underlying more detailed clinical data (Office of the Patient Advocate, 2003). ${ }^{11}$ Our analysis could be viewed as applying to a market such as California where the state is structuring the information available to consumers and employees.

Casting quality reports as a policy instrument turns up an important and simple conclusion: an averaged quality report can remedy adverse selection incentives in markets for health plans. The reasoning is straightforward. Averaging quality across its many dimensions and reporting only the average enforces pooling in health insurance. Choosing the weights in the average to reflect relative marginal benefits at the efficient quality mix ensures health plans allocate resources to elements qualities in the right way.

The power of quality reporting to correct selection-related incentives seems not to have been appreciated previously. For purposes of comparison, as we have shown here, in the canonical model of health insurance markets, an averaged quality report matches the performance of optimal risk adjustment.

\section{Acknowledgements}

Research support from the National Institute of Mental Health (R01 MH 59254, and R34 MH071242) and the Agency for Healthcare Research and Quality (P01 HS10803) is gratefully acknowledged.

\section{References}

Avery, C., Fairbanks, A., Zeckhauser, R., 2003. The Early Admissions Game: Joining the Elite. Harvard University Press, Cambridge, MA.

Beaulieu, N.D., 2002. Quality information and consumer health plan choices. Journal of Health Economics 21, 43-63.

Berkmeyer, J.D., et al., 2000. Leapfrog Safety Standards: The Potential Benefits of Universal Adoption. Leapfrog Group, Washington.

Cao, Z., 2003. Comparing Pre-HMO Enrollment Costs between Stayers and Switchers: Medicare Evidence of ServiceLevel Selection. Boston University.

\footnotetext{
${ }^{11}$ See also, California Health Care Performance Results Report on Quality, a publication of a collaborative coordinated by the Pacific Business Group on Health (2003).
} 
Cao, Z., McGuire, T.G., 2003. Service-level selection by HMOs in Medicare. Journal of Health Economics 22 (1), 89116.

Chernew, M., Gowrisankaram, G., McLaughin, C., Gibson, T., 2004. Quality and employer's choice of health plans. Journal of Health Economics 23 (3), 471-492.

Chernew, M., Scanlon, D., 1998. Health plan report cards and insurance choice. Inquiry 35, 9-22.

Clancy, C.M., Scully, T., 2003. A call to excellence: how the Federal Government's health agencies are responding to the call for improved patient safety and accountability in medicine. Health Affairs 22 (2), 113-115.

Classen, D., Kildgridge, P., 2002. The roles and responsibility of physicians to improve patient safety within healthcare delivery systems. Academic Medicine 77 (10), 963-972.

Cutler, D., Zeckhauser, R., 2000. The Anatomy of Health Insurance. North-Holland, Amsterdam.

Dranove, D., Kessler, D., McClellan, M., Satterthwaite, M., 2003. Is more information better? The effects of 'Report Cards' on health care providers. Journal of Political Economy 111 (3), 555-588.

Edgman-Levitan, S., Cleary, P.D., 1996. What information do consumers want and need? Health Affairs 15, 42-56.

Farley, D.O., Short, P., Elliot, M.N., Kanouse, D.E., Brown, J.A., Hays, R.D., 2002. Effects of CAHPS health plan performance information on plan choices by New Jersey medicaid beneficiaries. Health Services Research 37 (4), 985-1007.

Frank, R.G., Glazer, J., McGuire, T.G., 2000. Measuring adverse selection in managed health care. Journal of Health Economics 19 (November), 829-854.

Galvin, R., Milstein, A., 2002. Large employers' new strategies in health care. The New England Journal of Medicine 347 (12), 939-942.

Glazer, J., McGuire, T.G., 2000. Optimal risk adjustment of health insurance premiums: an application to managed care. American Economic Review 90 (4 September), 1055-1071.

Glazer, J., McGuire, T.G., 2001. Private employers don't need formal risk adjustment. Inquiry 38 (Fall).

Glazer, J., McGuire, T.G. What should consumers be told about product quality? Unpublished, 2003.

Hellinger, F., 1995. Selection bias in HMOs and PPOs. Inquiry 32, 135-142.

Hibbard, J., Jewett, J., 1996. What type of quality information do consumers want in a health care report card? Medical Care Research and Review 53, 28-47.

Hibbard, Judith, H., Harris-Kojetin, L., Mullin, P., Lubalin, J.S., Garfinkel, S.A., 2000. Increasing the impact of health plan report cards by addressing consumer concerns. Health Affairs 19 (5), 138-143.

Hirshleifer, J., 1971. The private and social value of information and the reward to inventive activity. American Economic Review 61, 561-574.

Institute of Medicine. Crossing the Quality Chasm. National Academy Press, Washington, DC, 2001.

Institute of Medicine. To Err is Human. National Academy Press, Washington, DC, 1999.

Keeler, E.B., Newhouse, J.P., Carter, G., 1998. A model of the impact of reimbursement schemes on health plan choice. Journal of Health Economics 17 (3), 297-320.

Keenan, P.S., Beeuwkes Buntin, M.J., McGuire, T.G., Newhouse, J.P., 2001. The prevalence of formal risk adjustment. Inquiry 38 (Fall (3)).

Luft, H.S., Miller, R.H., 1988. Patient selection and competitive health system. Health Affairs 7 (3), 97-112.

Mello, M.M., Stearn, S.C., Norton, E.C., 2002. Do Medicare HMOs still reduce health services use after controlling for selection bias? Health Economics 20 (11), 323-340.

Mirman, L., Samuelson, L., Schlee, E., 1994. Strategic information manipulation in duopolies. Journal of Economic Theory 62, 363-384.

Newhouse, J.P., 2002. Pricing the Priceless: A Health Care Conundrum. MIT Press, Cambridge, MA.

Newhouse, J.P., 1996. Reimbursing health plans and health providers: selection versus efficiency in production. Journal of Economic Literature 34 (3), 1236-1263.

Office of the Patient Advocate. California's Quality of Care Report Card 2003-2004. The State of California, 2003.

Pacific Business Group on Health. California Health Care Performance Results: Report on Quality, http://www.cchri.org/ reports/CCHRI_2003.pdf, 2003.

Pauly, M.V., 1985. What is Adverse about Adverse Selection? JAI Press.

Pauly, M.V., Ramsey, S.D., 1999. Would you like suspenders to go with that belt? An analysis of optimal combinations of cost sharing and managed care. Journal of Health Economics 18 (4), 443-458.

Rothschild, M., Stiglitz, J., 1976. Equilibrium in competitive insurance markets: an essay in the economics of imperfect information. Quarterly Journal of Economics 90, 629-649.

Sage, W.M., Hyman, D.A., Greenberg, W., 2003. Why competition law matters to health care quality. Health Affairs 22 (2), 31-44. 
Scanlon, D., Chernew, M., McLaughin, C., Solon, G., 2002. The impact of health plan report cards on managed care enrollment. Journal of Health Economics 21 (1), 19-41.

Schlee, E., 1996. The value of information about product quality. RAND Journal of Economics 27 (Winter (9)), 803815 .

Van de Ven, W.P., Ellis, R.P., 2000. Risk Adjustment in Competitive Health Plan Markets. North Holland.

Wedig, G.J., Tai-Seale, M., 2002. The effect of report cards on consumer choice in the health insurance market. Journal of Health Economics 21 (6), 1031-1048. 